János Kundrák, Athanasios G. Mamalis and Viktor Molnár

\title{
The efficiency of hard machining processes
}

ABSTRACT. The machining of hardened surfaces has increased significantly in the past years. While abrasive machining has held the lead up to now, the productivity of cutting by single-point tools is improving. In this paper the machining efficiency of surfaces of identical quality according to $R_{z}$ and international tolerance (IT) class was analysed after machining by various procedures: traverse bore grinding; hard turning by standard insert; and a joint procedure by standard insert in the hard turning operation. Based on an analysis of the material removal rate (MRR), environmental load and flexibility of machining, the procedures were ranked and recommendations were made for their application area considering the running conditions. It was found that the MRR is most favourable in the hard turning version. However, if the running conditions of the built-in part require a random topography, the most efficient version is the joint procedure.

Nanotechnology Perceptions 15 (2019) 131-142

doi: 10.4024/N05KU19A.ntp.15.02 